\title{
EFFECTS OF ORAL ADMINISTRATION OF PHYLLANTHUS AMARUS LEAF EXTRACT ON THE KIDNEYS OF ADULT WISTAR RATS- A HISTOLOGICAL STUDY
}

\author{
*A.O. Eweka and Adaze Enogieru \\ Department of Anatomy, School of Basic Medical Sciences \\ University of Benin, Edo state, Nigeria. \\ "E-mail: andreweweka@yahoo.com
}

\begin{abstract}
Histological studies of the effects of oral administration of aqueous extract of Phyllanthus amarus commonly used in ethno medical practice in Africa for the management of various ailments such as kidney stones, dysentery, jaundice, diarrhoea and urogenital diseases on the kidney of adult Wistar rats were carefully studied. Rats of both sexes $(n=24)$, average weight of $260 \mathrm{~g}$ were randomly assigned into three groups: A, B and C of $(n=8)$ in each group. Group A and B served as treatment groups $(n=16)$ while group C $(\mathrm{n}=8)$ served as the control. The rats in the treatment groups (A \& B) received 500 mg/kg and 1000mg/kg body weight respectively of aqueous extract of Phyllanthus amarus orally through orogastric tube for twenty-eight days, while the control rats received equal volume of distilled water without the extract of Phyllanthus amarus added for the same period. The rats were fed with growers' mash purchased from Edo feeds and Flour Mill Ltd, Ewu, Edo state and were given water liberally. The rats were sacrificed on day twenty-nine of the experiment. The kidneys were carefully dissected out and quickly fixed in $10 \%$ formal saline for routine histological study after H\&E method. The histological findings indicated that the treated sections of the kidneys showed hypertrophy of blood vessels, mild-severe infiltrate of chronic inflammatory cells and varying degrees of tubular necrosis when compared to the control sections. The findings indicated that the administration of Phyllanthus amarus extract has some adverse effects on the kidneys of adult Wistar rats. It is recommended that further studies aimed at corroborating these observations be carried out.
\end{abstract}

Keywords: Phyllanthus amarus, Histological effects, Kidneys, Urogenital diseases, chronic inflammatory cells, tubular necrosis, Wistar rats.

\section{Introduction}

Plant materials as sources of medical compounds continue to play a dominant role in the maintenance of human health since antiquity. Over 50\% of all modern chemical drugs are of natural plant product origin, and is essential in drug development programs of the pharmaceutical industry (Burton et al., 1983). Like any therapeutic agent, when overdosed or incorrectly used they also have the potential to induce adverse effects. The historic role of medicinal herbs in the treatment and prevention of disease, and their role as catalysts in the development of pharmacology do not, however, assure their safety for uncontrolled use by an uninformed public (Matthews et al., 1999).

Phyllanthus amarus ( $P$. amarus) is a broad spectrum medicinal plant that has received world- wide recognition (Srividiya and Perival, 1995). In Nigeria, it is called "Oyomokeisoamankedem" in Efik, "Iyin Olobe" in Yoruba and "Ebebenizo" in Bini (Etta, 2008). P. amarus is generally employed to reduce pain, expel intestinal gas, to stimulate and promote digestion, as anti-helminthes to expel intestinal worms and act as a mild Laxative. P. amarus also has antiseptic, diuretic, antiviral, anti-diabetic, hypotensive and antipyretic properties, and is also used in the treatment of jaundice, diarrhoea, dysentery, wound, ulcers and urogenital diseases (Calixto et al., 1998; Santos et al., 1995). The plants of the genus Phyllanthus are widely distributed in most tropical and subtropical countries and have long been used in traditional medicine to treat chronic liver disease (Liu et al., 2003).

Plants contain numerous constituents; some tend to possess some level of toxicity. Cases of this toxicity in plants have been reported (Santos et al., 1995; Shaw et al., 1997; Kaplowitz, 1997). P. amarus has been classified among plants with a low potential for toxicity, with an $\mathrm{LD}_{50}$ averaging $2000 \mathrm{mg} / \mathrm{kg} / \mathrm{day}$ (Krithika and Verma, 2009). The phytochemical analysis of the $P$. amarus extract confirmed the presence of tannins, saponins, flavonoids and alkaloids. The plant extract have been found to contain high levels of saponins, tannins, flavonoids and alkaloids (Fernand, 1998; Naaz, 2007; Krithika and Verma, 2009).

The histological effects of $P$. amarus on the kidneys have not been widely elucidated, as very few literature reports have been documented (Etta, 2008; Adeneye and Benebo, 2008). The traditional uses of $P$. amarus for kidney stones and gall bladder stones have been validated by clinical research, where $P$. amarus extract was found to exhibit a potent and effective nonconcentration dependent inhibitory effect on calcium oxalate crystal formation, the building blocks of most kidney stones (Calixto, 2000). This response was present even at a very high (pathogenic) concentration. This may explain why it has long been used in traditional medicine as prevention against kidney stone formation (Campos and Schor, 1999). P. amarus has been found 


\section{Eweka and Enogieru Afr J Tradit Complement Altern Med. (2011) 8(3):307 - 311308}

to be $94 \%$ successful in eliminating stones (Maxwell, 1990). Some Brazilian researchers in the mid 1980's reported on the antispasmodic activities of alkaloids in P. amarus, this explained the popular use of the plant for the expulsion of kidney and bladder stones. The alkaloid extract demonstrated smooth muscle relaxation specific to the urinary and biliary tract which the researchers surmised facilitates the expulsion of kidney and bladder calculi (Miller, 1998; Calixto, 1984).

This work was performed in order to investigate potential histological effects of Phyllanthus amarus leaf extracts on the kidneys of adult Wistar rats.

\section{Materials and Methods Plant Materials}

Fresh leaves of Phyllanthus amarus (voucher number UBAD-Pa 001) were collected in December, 2009 at Iduonomwina town, Ovia North-East local government area of Edo State. The plant was identified and authenticated at the Botany Department of University of Benin, Benin City. The harvested fresh leaves were sun dried and ground into a fine powder. The dried material (800g) was macerated in 10 liters of distilled water for $48 \mathrm{hrs}$ at $4 \mathrm{oC}$ in a refrigerator. The extract was sieved and the juice was filtered using Whatman No 1 filter paper. The filtrate was placed in a stainless-steel tray, and concentrated in an air-circulating oven at $42^{\circ} \mathrm{C}$ until totally dry. The resultant extract $(18 \mathrm{~g})$ was placed into small glass dishes and stored at $28^{\circ} \mathrm{C}$ in an incubator for further studies.

\section{Animals}

Twenty-four, (24) adult Wistar rats of both sexes, with an average weight of $260 \mathrm{~g}$ were randomly assigned into three groups: A, B and C of $(n=8)$ in each group. Group A and B served as treatment groups $(n=16)$ while group $C$ ( $n=8)$ served as the control. The rats were obtained and maintained in the Animal Holdings of the Department of Anatomy, School of Basic Medical Sciences, University of Benin, Benin City, Nigeria. They were fed with growers' mash obtained from Edo feed and flour mill limited, Ewu, Edo State and given water liberally. The rats gained maximum acclimatization (4 weeks) before actual commencement of the experiment.

\section{Phyllanthus amarus administration}

The rats in the treatment groups (A \& B) received $500 \mathrm{mg} / \mathrm{kg}$ body weight and $1000 \mathrm{mg} / \mathrm{kg}$ body weight respectively of aqueous extract of Phyllanthus amarus orally through an orogastric tube on a daily basis. The control group received an equal volume of distilled water without the extract of $P$. amarus added for twenty-eight days.

\section{Histological Study}

Blood samples were collected and analyzed for blood urea nitrogen (BUN) and serum creatinine (Scr) by using the commercial kits (McClatchey, 1994) on the twenty-nine day of the experiment. After bleeding, the rats were sacrificed by cervical dislocation and the abdominal cavity was opened up using a pair of forceps to expose the kidneys which were quickly dissected out and fixed in 10\% formal saline for routine histological techniques. The tissues were dehydrated in an ascending grade of alcohol (ethanol), cleared in xylene and embedded in paraffin wax. Serial sections of 7 microns thick were obtained using a rotatory microtome. The deparaffinized sections were stained routinely with hematoxylin and eosin (H\&E) method (Drury et al., 1967). Photomicrographs of the desired sections were made for further observations.

Approval: This study was given consent and approval for the methodology and other ethical issues concerning the work by the University of Benin Research Ethics Committee.

\section{Statistical analysis}

The results were expressed as mean \pm SD. Data was analyzed by one-way analysis of variance. Sequential differences among means were calculated at the level of $\mathrm{P}<0.05$, using Turkey contrast analysis as needed.

\section{Result}

The result of this experiment revealed that administration of $P$. amarus caused significant $(\mathrm{P}<0.05)$ increase in functional nephrotoxicity indicators such as BUN and Scr in P. amarus -treated rats compared with control (Table 1). The control sections of the kidneys showed normal histological features. The section indicated a detailed cortical parenchyma and the renal corpuscles appeared as dense rounded structures with the glomerulus surrounded by a narrow Bowman's spaces. (Figure 1)

The kidneys of the animals in group 'A' treated with $500 \mathrm{mg} / \mathrm{kg}$ body weight of $P$. amarus revealed some level of cyto-architectural distortion of the cortical structures :- vascular hypertrophy, interstitial oedema, mild chronic inflammatory infiltrates and haemorrhage as compared to the control (Figures 2 \& 3). The kidney sections of animals in group 'B' treated with 
$1000 \mathrm{mg} / \mathrm{kg}$ body weight day of $P$. amarus revealed marked distortion of cyto-architecture of the renal cortical structures, and degenerative and atrophic changes. There were tubular necrosis, interstitial haemorrhage, moderate-severe chronic inflammatory cell infiltrates, vascular hypertrophy, and vacuolations appearing in the stroma. (Figures 4 \& 5)

\section{Legend to figures:}

Figure1: Control section of kidney; this shows cortical parenchyma to consist of dense rounded structures, the glomeruli, surrounded by narrow Bowman's capsular spaces. H\&E (Mag. X400)

Figures 2 \& 3: Photomicrograph of treatment sections of the kidney of rats that received $500 \mathrm{mg} / \mathrm{kg}$ body weight of $P$. amarus revealing some level of cyto-architectural distortion. H\&E (Mag. X400)

Figures 4 \& 5: Treatment sections of the kidney of rats that received $1000 \mathrm{mg} / \mathrm{kg}$ body weight of $P$. amarus, revealing moderatesevere level of cyto-architectural distortion, degenerative and atrophic changes, and vacuolations appearing in the stroma. H\&E (Mag. X400)

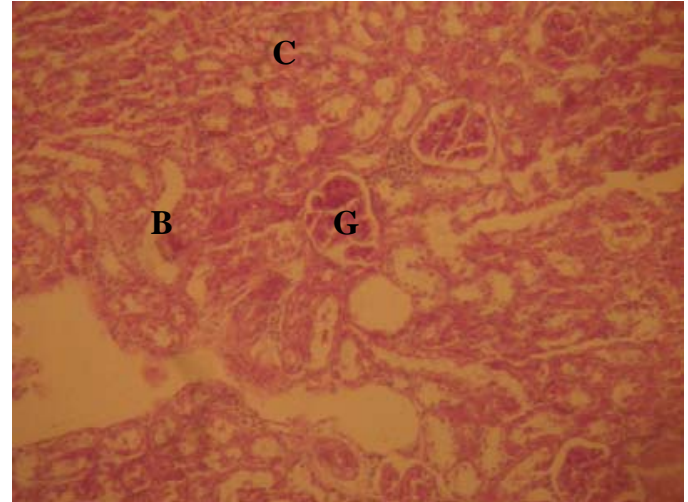

Figure 1: Normal kidney showing glomeruli (G), cortical (B) and medullary tubules (C). [H\&E]

Mag. x 400

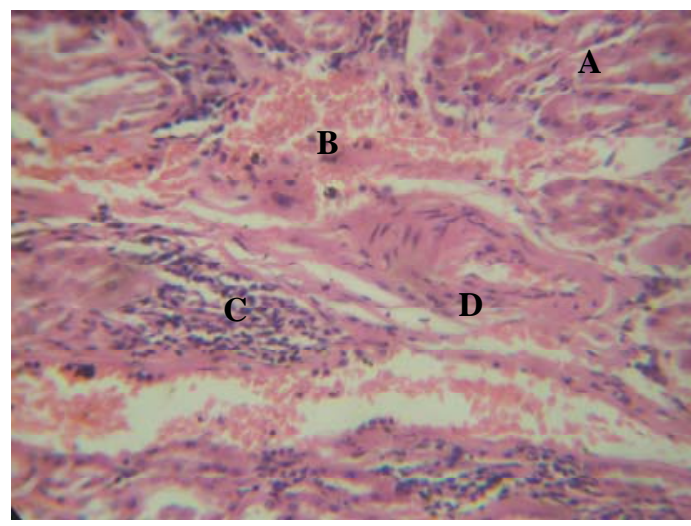

Figure 3: Group ' $A$ ' treated kidney showing

Tubular necrosis (A), interstitial haemorrhage(B)

Mild chronic inflammatory cell infiltrates(C) and

Vascular hypertrophy (D) [H\&E x 400]

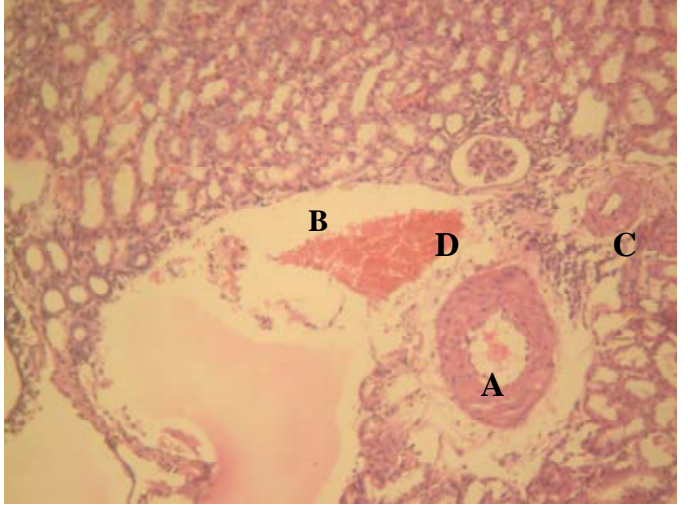

Figure 2: Group “A” treated kidney showing vascular hypertrophy (A), interstitial oedema (B), chronic inflammatory infiltrates (C) and haemorrhage (D) [H\&E x 400]

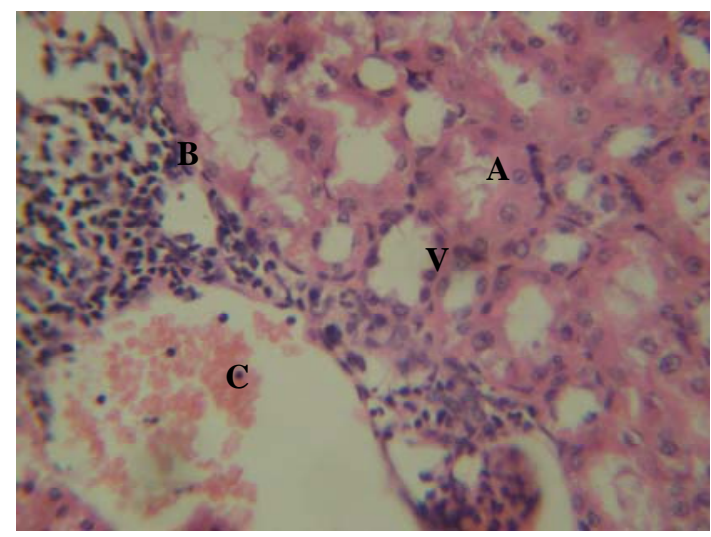

Figure 4: Group ' $\mathrm{B}$ ' treated kidney showing tubular necrosis (A), interstitial haemorrhage (B) and moderate-severe chronic inflammatory cell infiltrates (C), and vacuolation (V) in the stroma [H\&E x400] 


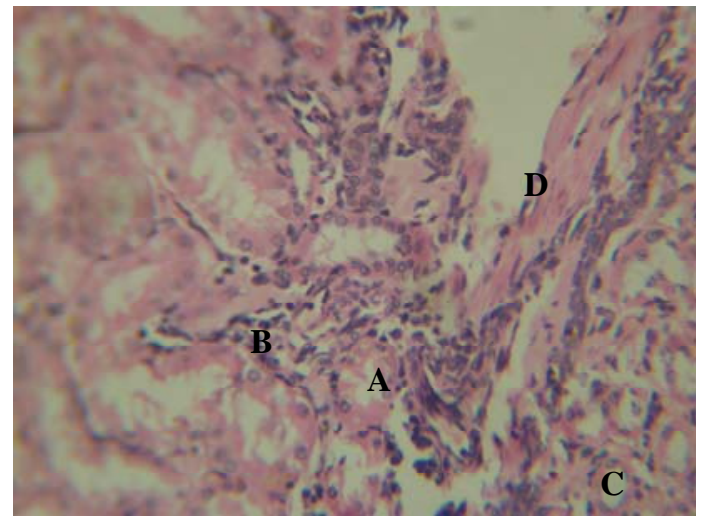

Figure 5: Group 'B' treated kidney showing tubular necrosis (A), moderate-sever chronic inflammatory cell infiltrates (B), vacuolations (C) and interstitial fibrosis (D)[H\&E x400]

Table 1: effects of Phyllanthus amarus administration $(500 \mathrm{mg} / \mathrm{kg}$ and $1000 \mathrm{mg} / \mathrm{kg})$ on BUN and Scr concentration

\begin{tabular}{|l|l|l|}
\hline & BUN $(\mathrm{mg} / \mathrm{dl})$ & Scr $(\mathrm{mg} / \mathrm{dl})$ \\
\hline Control & $14.34 \pm 2.4$ & $0.71 \pm 0.24$ \\
\hline Experimental group A (500mg/kg) & $26.6 \pm 4.26$ & $1.72 \pm 2.64$ \\
\hline Experimental group B (1000mg/kg) & $63 \pm 1.23$ & $3.7 \pm 3.93$ \\
\hline
\end{tabular}

$\mathrm{n}=24$, mean \pm SD; $P<0.05$ significantly different compared with nutmeg-treated group.

\section{Discussion}

The result (H\&E) revealed that administration of Phyllanthus amarus caused varying degree of cyto-architectural distortion and vasculogenic effect on the kidney which affected blood vessels, haemorrhagic and chronic inflammatory cells appearing in the treatment groups compared to the control group. Narrowing of the lumen also occurred with associated hypertrophic blood vessels and haemorrhage extending into the interstitium. There were several diffuse degeneration and necrosis of the tubular epithelial cells in the kidneys of the treated animals $(500-1000 \mathrm{mg} / \mathrm{Kg})$. The degenerative and atrophic changes where observed more in the kidneys of rats that received the higher dose $(1000 \mathrm{mg} / \mathrm{kg})$ of P. amarus .

It may be inferred from the present results that higher doses of $P$. amarus may have resulted in degenerative and atrophic changes observed in the renal corpuscle. The histological effects observed in this experiment is in consonance with the report of Manjrekar et al. who observed that $P$. amarus induced deleterious changes on the renal tubules and testes of male rats (Manjrekar et al., 2008; Adedapo et al., 2005). It is noteworthy that $P$. amarus contains alkaloids and lots of antioxidants (Fernand, 1998; Naaz, 2007; Krithika and Verma, 2009), which has been given to apparently healthy animals. Our observation is consistent with the notion that antioxidant is associated with toxicities especially if taken arbitrarily (Miller, 2005). Although, antioxidants are essential for alleviation of oxidative stress, indiscrete intake of alkaloids and antioxidant constituents of $P$. amarus may present their toxic effects by inducing oxidative stress (Atici et al., 2005; Galati and O'Brien, 2004). The possible deduction from these results is that secondary metabolites, which are largely responsible for therapeutic or pharmacological activities of medicinal plants (Perry, 1980), may also account for their toxicity when the dosage is abused. The actual mechanism by which $P$. amarus induced cellular degeneration observed in this experiment needs further investigation.

The importance of this report lies in the potential adverse effects of $P$. amarus on the microanatomy of tissues and organs. In the kidney, it has been indicated to cause necrosis and protein casts in the kidney tubules (Manjrekar et al., 2008; Adedapo et al., 2005). The necrosis observed is probably due to the high concentration of $P$. amarus on the kidney.

Pathological or accidental cell death is regarded as necrotic and could result from extrinsic insults to the cell as osmotic thermal, toxic and traumatic effect (Farber et al., 1981). Physiological cell death is regarded as apoptotic and organized programmed cell death (PCD) that is mediated by active and intrinsic mechanisms. The process of cellular necrosis involves disruption of membranes, as well as structural and functional integrity. Cellular necrosis is not induced by stimuli intrinsic to the cells as in programmed cell death (PCD), but by an abrupt environmental perturbation and departure from the normal physiological conditions (Farber et al., 1981).

In cellular necrosis, the rate of progression depends on the severity of the environmental insults: the greater the severity of the insult, the more rapid the progression of cellular injury. The principle holds true for toxicological insult to the brain and other organs (Martins et al., 1998). It may be inferred from the present study that prolonged administration and higher doses of $P$. amarus resulted in increased toxic effect on the kidney. 


\section{Conclusion and recommendation}

The results obtained in this study revealed that administration of $P$. amarus could affect the histology of the kidney of adult Wistar rat; causing disruptions and distortions of the cyto-architecture of the kidneys despite the fact that $P$. amarus is known to eliminate gall stones, kidney stones and other kidney related problems (Heyde, 1990). These results suggest that the functions of the kidney may have been adversely affected. It is recommended that caution should therefore be advocated in the intake of this product and further studies be carried out to examine these findings.

\section{References}

1. Adedapo, A.A., Adegbayibi, A.Y., Emikpe, B.O. (2005). Some clinico-pathological changes associated with the aqueous extract of the leaves of Phyllanthus amarus in rats. Phytother Res.; 19: 971-976.

2. Adeneye, A.A., Benebo, A.S. (2008). Protective effect of the aqueous leaf and seed extract of Phyllanthus amarus on gentamicin and acetaminophen-induced nephrotoxic rats. Journal of Ethnopharmacology, Volume 118, Issue 2, Pages 318-323

3. Atici, S., Cinel, I., Cinel, L., Doruk, N., Eskandari, G., Oral, U. (2005). Liver and kidney toxicity in chronic use of opioids: An experimental long term treatment model. J Biosci; 30: 245-252.

4. Burton, G.W., Joyce, D., Ingold, K.U. (1983). Is Vit. E the only lipid soluble chain having anti-oxidant activity in human blood plasma and erythrocyte. Arch. Biochem Biophys., (2) 22; 228-290.

5. Calixto, J.B. (1984). Antispasmodic Effects of an alkaloid extracted from Phyllanthus sellowianus; a comparative study with papaverine. Brazilian Journal of Medical and biological Research 17(3-4): 313- 397.

6. Calixto, J.B., Santos, A.R.S, Cechinel-Filho, V., Yunes, R. A. (1998). A Review of the plants of the Genus Phyllanthus: their Chemistry, Pharmacology and Therapeutic Potential. Med. Res. Rev. 18: 225-258

7. Calixto, J.B. (2000). Efficacy, safety, Quality Control, Marketing and Regulatory Guidelines for Herbal Medicines (Phytotherapeutic Agents). Braz. J. Med. Biol. Res. 3: 179-189.

8. Campos, A.H, Schor, N. (1999). Phyllanthus niruri inhibit Calcium Oxalate Endocytosis by Renal Tubular Cells; Its role in Urolithiasis. 81(4): 393- 397

9. Drury, R.A.B., Wallington, E.A., Cameron, R. (1967). Carleton's Histological Techniques, $4^{\text {th }}$ ed., Oxford Univ. Press. NY. USA, $279-280$.

10. Etta, H. (2008). Effects of Phyllanthus amarus on litter traits in albino rats Scientific Research and Essay Vol. 3 (8), pp. $370-372$.

11. Farber, J.L., Chein, K.R., Mittnacht, S. (1981). The pathogenesis of irreversible cell injury in ischemia. American Journal of Pathology; 102:271-281.

12. Fernand, V.E. (1998). Initial characterization of crude extracts from Phyllanthus amarus schum and thonn and Quassia amara L. using normal phase thin layer chromatography [Thesis]. Louisiana State University; pp6-13.

13. Galati, G., O'Brien, P.J. (2004). Potential toxicity of flavonoids and other dietary phenolics: significance for their chemopreventive and anticancer properties. Free Radic Biol Med.; 37: 287-303.

14. Heyde, H. (1990). Medicijn planten in Suriname. (Den dresi wiwiri foe Sranan). "Medicinal Plants in Suriname.” Uitg. Stichting Gezondheidsplanten Informaite (SGI). Paramaribo. pp 157

15. Kaplowitz, N. (1997). Hepatotoxicity of Herbal Remedies. Insight into the intricacies of plant- animal warfare and Cell Death. Gastroenterology. 113: $1408-1412$.

16. Krithika, R., Verma, R. J. (2009). Mitigation of carbon tetrachloride-induced damage by Phyllanthus amarus in liver of mice. Acta Pol Pharm. 2009 Jul-Aug; 66(4):439-44.

17. Lui, R-LH., Huang, Y.L. (2003). Genus Phyllanthus for chronic hepatitis B virus infection: A systemic review. Viral Hepatitis (8): 358-366.

18. Matthews, H.B., Lucier, G.W., Fisher, K.D. (1999). Medicinal herbs in the United States: Research Needs. Environ. Health Perspect., 107, 773-778.

19. Manjrekar, A.P., Jisha, V., Bag, P.P., Adhikary, B., Pai, M.M., Hegde, A., et al., (2008). Effect of Phyllanthus niruri Linn treatment on liver, kidney and testes in CCl4 induced hepatotoxic rats. Indian J Exp Biol. 46: 514-520.

20. Martins, L.J., Al-Abdulla, N.A., Kirsh, J.R., Sieber, F.E., Portera-Cailliau, C. (1998). Neurodegeneration in excitotoxicity, global cerebral ischaemia and target. Deprivation: A perspective on the contributions of apoptosis and necrosis. Brain, Res. Bull., 46(4): 281-309.

21. Maxwell, N. (1990). Witch Doctors's Apprentice, Hunting for Medicinal Plants in the Amazon, $3^{\text {rd }}$ Edition. Citadel press, New York.

22. McClatchey, K.D. (1994). Clinical Laboratory Medicine London Williams \& Wilkins.

23. Miller, L.G. (1998). Herbal medicines: Selected Clinical Considerations Focusing on known or Potential Drug-Herb interactions. Arch. Intern. Med., 158, 2200-2211.

24. Miller, E.R., 3rd, Pastor-Barriuso, R., Dalal, D., Riemersma, R.A., Appel, L.J., Guallar, E. (2005). Meta-analysis: high-dosage vitamin E supplementation may increase all-cause mortality. Ann Intern Med; 142: 37-46.

25. Naaz, F., Javed, S., Abdin, M.Z. (2007). Hepatoprotective effect of ethanolic extract of Phyllanthus amarus Schum. et Thonn. on aflatoxin $\mathrm{B}_{1}$-induced liver damage in mice. J Ethnopharmacol; 113: 503-509.

26. Perry, L.M. (1980). Medicinal plants of East and South East Asia, MIT Press, Cambridge Massachusetts.

27. Santos, A.R.S, Ailho, V.C, Yunes, R.A, Calixto, J.B. (1995). Analysis of the mechanism underlying the Anti-nociceptive Effect of the Extracts of plants from the Genus Phyllanthus. General Pharmacol. 26: 1499- 1506

28. Shaw, D., Leon, C., Koleu, S., Murray, V. (1997). Traditional Remedies and Food Supplements. A Five- year Toxicology Study (1991, 1995). Drug Safety. 17: 342- 356.

29. Srividiya, N., Perival, S. (1995). Diuretic, Hypotensive and Hypoglycemic Effect of Phyllanthus Amarus. Indian Journal of Experimental Biology. 33(11): pp 861-864 